JHLSCM

11,3

550

Received 3 November 2020 Revised 16 February 2021 7 April 2021

Accepted 7 April 2021

\title{
Humanitarian logistics and supply chain standards. Literature review and view from practice
}

\author{
Claudia Paciarotti \\ Dipartimento di Ingegneria Industriale e Scienze Matematiche, \\ Università Politecnica delle Marche, Ancona, Italy \\ Wojciech D. Piotrowicz \\ Hanken School of Economics, HUMLOG Institute, Helsinki, Finland, and \\ George Fenton \\ Humanitarian Logistics Association, Corby, UK
}

\begin{abstract}
Purpose - The paper is focused on standards in humanitarian logistics and supply chain. Standards, implemented between organisations, allow improving the interoperability of humanitarian operations. The paper aims (1) to review a state-of-the-art approach to the topic by the academic community, (2) to evaluate the current use of standards among humanitarian organisations and (3) to investigate the perceived need for further and specific standards.

Design/methodology/approach - To achieve the aims, the literature was reviewed; then a survey on 227 professionals from the humanitarian logistics sector was conducted.

Findings - Based on 227 responses, it is possible to conclude that most surveyed professionals recognise the need for and the importance of standardisation in humanitarian logistics, especially in areas such as procurement, distribution, medical logistics and logistics planning, which were perceived as critical areas that require standardisation.

Research limitations/implications - Practitioners and scholars were targeted via social media, through mailing lists and via communication from the practitioner organisation - the Humanitarian Logistics Association (HLA). While it provided good access to different groups of respondents, the response rate is not possible to calculate.

Practical implications - The findings confirm the high importance of standardisation, indicating areas and functions that should be standardised first. Standardisation may improve cooperation between different humanitarian actors, allowing better service provision for beneficiaries. Thus there are also potential negative impacts, i.e. impact on localisation, which should be overcome.

Social implications - Results do not have a direct social impact; however, they stimulate research and work among practitioners on standardisation, which in turn could improve cooperation between humanitarian actors, thereby enabling a better humanitarian response in emergencies.

Originality/value - The majority of papers on standardisation use a qualitative approach. This paper applies a survey among a large network of humanitarian practitioners, capturing their view on the topic and perception of the need for standardisation. The work is descriptive; however, it could be used as a base for further studies related to humanitarian standards.
\end{abstract}

Keywords Humanitarian logistics, Standard, Humanitarian supply chain

Paper type Research paper

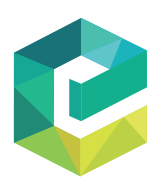

Journal of Humanitarian Logistics and Supply Chain Management Vol. 11 No. 3,2021 pp. 550-573 Emerald Publishing Limited 2042-6747

DOI 10.1108/JHLSCM-11-2020-0101

\section{Introduction}

In the aftermath of a disaster, promptness and appropriateness in supplying people in need with the required assistance (e.g. shelter, food and non-food items, medicine and water) is

(C) Claudia Paciarotti, Wojciech D. Piotrowicz and George Fenton. Published by Emerald Publishing Limited. This article is published under the Creative Commons Attribution (CC BY 4.0) licence. Anyone may reproduce, distribute, translate and create derivative works of this article (for both commercial and non-commercial purposes), subject to full attribution to the original publication and authors. The full terms of this licence may be seen at http://creativecommons.org/licences/by/4.0/legalcode 
crucial (Thomas and Kopczak, 2005). Humanitarian logistics has a decisive impact on the effectiveness and efficiency of humanitarian actions and logistics accounts for up to $80 \%$ of the costs of relief operations (Tomasini and Van Wassenhove, 2009). Although the growth of cash-based initiatives, the importance of goods transportation, logistics and supply chain is still not challenged, especially at the early response phase (Piotrowicz, 2018). The management of humanitarian logistics and supply chain presents significant challenges. The humanitarian system is a complex one; this is determined by a frequently sudden need to re-establish supply chain flows after a disaster, also by the variety of actors (Figure 1) involved in the humanitarian aid supply network (Oloruntoba and Gray, 2006; van Wassenhove, 2006; Kovács and Spens, 2009).

These humanitarian actors have distinct characteristics. They could have different geographical coverage (some actors act at regional and local levels, others operate at national and some at a global level). Furthermore, these actors can also be broadly different in nature, size, approach, mission, specialisation, rules and regulations and scope of operations. Moreover, a humanitarian system is composed of a number of individualistic actors with self-sufficient perspectives (Maon et al., 2009), and they might become potential “competitors" (Fritz Institute, 2004). The presence of such a high number of differentiated and individualistic stakeholders raises the issue of better coordination of the relief chains and highlights the need for standards able to provide a shared language and shared understanding of procedures and processes. The need for coordination will grow in the coming years also as a consequence of the increasing attention to localisation in the humanitarian sector since the 2016 Global Humanitarian Summit (WHS, 2016). Localising humanitarian response is "a process of recognising, respecting and strengthening the leadership by local authorities and the capacity of local civil society in humanitarian action, in order to better address the needs of affected populations and to prepare national actors for future humanitarian responses." (OECD, 2017). In practical terms this implies a greater and greater involvement of a plethora of different actors such as national authorities in aid recipient countries, national Societies of the Red Cross /Crescent, national/subnational/local non-governmental organisations (NGOs)/civil society organisations (CSOs), local and national private sector organisations (OECD, 2017). The resulting increasing complexity and necessity to cooperate adopting a shared "language" increasingly emphasises the importance of widespread and shared standards. Usage of standardised processes, procedures,

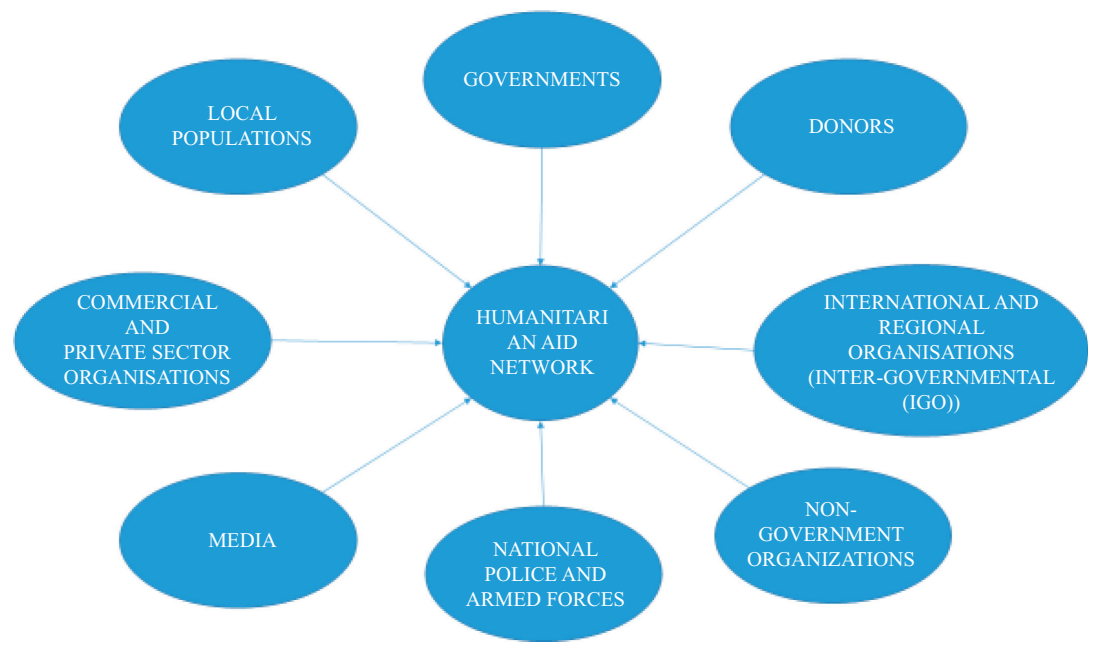

Standards in humanitarian supply chain
Figure 1 . Humanitarian operations actors 
JHLSCM 11,3

common templates, etc. increases interoperability between organisations, allowing coordination of the efforts between international and local partners.

The importance of coordination of humanitarian actors strongly emerged after the response to the Rwanda humanitarian crisis that began in 1994. In 1996, the problems and inefficiencies faced during this crisis determined the decision to launch the Sphere project, with the first set of minimum standards published and applied in 1998 (O'Donnell et al., 2002). In January 2000, the Sphere project published the first handbook identifying a set of a minimum standard in key lifesaving sectors to be achieved by emergency relief programs in order to improve the quality and accountability of NGOs for their actions in humanitarian responses. Minimum standards are set in four key response sectors: (1) water supply; (2) sanitation and hygiene promotion (WASH); (3) food security and nutrition; (4) shelter, settlement and health. In the following years, other standards have been developed adopting a similar approach, that is, via inclusive consultation processes with a wide group of practitioners. Currently, the Sphere, in coalition with other six standards initiatives: (1) minimum standards for child protection in humanitarian action, (2) livestock emergency guidelines and standards, (3) minimum economic recovery standards, (4) minimum standards for education, (5) minimum standard for market analysis and (6) humanitarian inclusion standards for older people and people with disabilities, constitutes the humanitarian standards partnership. Despite that many areas of humanitarian operations are covered by this group of approved and widespread initiatives, the humanitarian logistics and supply chain are not yet deeply involved in this standardisation process. Due to the previous consideration and the central role played by the humanitarian logistics and supply chain, the aim of the paper is to:

(1) identify current knowledge and approaches to the topic by the academic community,

(2) evaluate the current use of standards by humanitarian logistics practitioners,

(3) investigate the perceived need for further humanitarian logistics and supply chain standards (HLSCS).

Section 2 aims to analyse how the scientific community handles the topic of humanitarian logistics and supply chain standards based on the literature review. Section 3 illustrates the research method, and section 4 summarises the main results of the analysis. Conclusions and suggestions for the required further steps are included in section 5.

\section{Humanitarian logistics standards: state of the art}

Standardisation in logistics is perceived as a way to improve performance (Fabbe-Costes et al., 2006). This is also visible in humanitarian logistics and supply chain. In 2004, during the Africa Regional Humanitarian Logistics Conference, logisticians shared their experiences and views on local and regional disaster response, with the aim of exploring ways to improve logistics processes in the African context. One of the biggest challenges for humanitarian logisticians that emerged during the discussion was the lack of standards, since standardisation among relief organisations was missing (Fritz Institute, 2004). Seven years later, Kovàcs and Spens wrote the first editorial of the Journal of Humanitarian Logistics and Supply Chain Management (2011a) and identified research gaps in humanitarian logistics and supply chain management: product and process standardisation were among them. Standardisation was indicated as a future research area because of its capability of improving the interoperability of humanitarian operations. The authors further deepened the gap analysis in humanitarian logistics (Kovàcs and Spens, 2009): they collected data from the websites of humanitarian organisations and documents from workshops and seminars with practitioners. Some of the gaps detected for humanitarian logistics practice were directly 
connected with the need for standards. The development of common templates such as in needs assessment, ordering and tracking would facilitate the interoperability of humanitarian organisations. Moreover, addressing topics such as product and packaging standardisation could simplify shared transportation.

A standard is "a rule approved by a recognized body that provides non-compulsory rules, guidelines, or characteristics for products, processes, or services" (Jahre and Fabbe-Costes, 2015). "Standard denotes a technical reference level of quality or attainment. The standards are qualitative and universal in nature and are applicable in any operating environment as they specify the minimum level to be attained" (WHO, 2007). As it stems from the previous paragraph, the development and implementation of standards is an emerging, challenging and ongoing process in the humanitarian field. Larson and Foropon (2018) identified three reasons explaining the importance of standards for humanitarian NGOs: high personnel turnover, donor reporting requirements and the focus on providing efficient and high-quality assistance to beneficiaries. From a content analysis on a sample of humanitarian NGO annual reports and webpages of eight Canadian and eight French NGOs, it appears that contingency factors such as organisational size and the scope of operations are connected to the use of standards (Larson and Foropon, 2018). In particular, larger NGOs with a broader operational scope and NGOs with secular missions (as opposed to religious or faith-based NGOs) are more likely to employ formal standards.

Jahre and Fabbe-Costes (2015) introduced a framework for the classification of standards in the humanitarian context. The standards are divided into two main categories: physical and organisational standards (Table 1).

From the proposed categorisation, it emerges that there are numerous areas that could be shaped and improved by a standardisation process. Furthermore, in the same paper, the authors conducted an explorative case on the health emergency response unit (ERU) in the Norwegian Red Cross. The study highlighted that the ERU uses many logistics and supply chain standards, and some of them have not been previously mentioned and identified in the literature. This finding reconfirms the vastness and the potentialities of the topic.

Standardisation of operations in emergency settings was also reviewed by Ye et al. (2020) who distinguish standardisation on operations, but also training and information technology. The lack of standardisation is listed among factors that negatively influence the ability to provide services to beneficiaries, with outcomes such as inefficiencies, duplications and overlaps in actions by different humanitarian actors. Standards should also be used when field logistics sites are selected for staging areas. Such standards should be part of wider emergency response plans (Kapucu et al., 2007; Kapucu, 2006).

Most authors adopted a case study research approach in order to deeply understand the phenomenon of logistics standardisation in the humanitarian context, or to identify and interpret the associated elements such as effects, benefits, weaknesses and difficulties in implementation. The analysis of case studies enables the focussing on problems emerging from a lack of standardisation in a real humanitarian context and, on the other hand, on the benefits connected to a well-done implementation of standards.

Kumar et al. (2009) presented the case of Global Health Ministries, an NGO which gathers and distributes donated healthcare equipment and supplies to countries in need. Donations delivered to the organisation are inspected, sorted and stored by volunteers, and before the shipping, they are packaged in reused boxes. The lack of standardisation in packaging affects difficulties in loading containers efficiently, and some customs found boxes contents differ from those indicated in the label. To avoid such problems, the authors recommended the use of standard boxes in the supply process. The use of standardised packaging for products sent in an emergency context could also facilitate shared transportation (Kovács and Spens, 2009).

A health commodities management system for HIV/AIDS in Nigeria was analysed by Ibegbunam and McGill (2012). They focused on health supply chain strategies and revealed
Standards in humanitarian supply chain 


\section{JHLSCM 11,3}

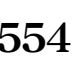

Table 1.

Logistics standard classification
Physical standards

Product standardisation

Packaging standardisation

Standard relief items

Standardised kits

Standard selection of relief goods

Standardisation for equipment

Standard infrastructures for

commodity management

Warehouse standardisation

Telecommunication standards

Process, procedures, tools and practices
Service

Information system

$\begin{array}{ll}\text { Service } & \text { Service standardisation } \\ \text { Human resources } & \text { Standardised training } \\ & \text { Standardisation of language } \\ & \text { Common standard of cross-functional } \\ & \text { skills development } \\ & \text { Community-wide skills standards } \\ & \text { Basic logistics information standards } \\ & \text { Standardised structure of information } \\ \text { Information system } & \text { Sharing and communication protocols } \\ & \text { Track and trace standard } \\ & \text { Standardised information system } \\ & \text { Standard indicators to measure } \\ \text { Performance measuremente and metrics } \\ \text { Process, procedures, tools } \\ \text { Standard measurement systems } \\ \text { Accountability standards } \\ \text { Process standardisation } \\ \text { Standard operating procedures } \\ \text { Standards in humanitarian practice } \\ \text { Standard methodology in project } \\ \text { management } \\ \text { Standard set of tools logistics } \\ \text { guidelines) } \\ \text { Standard logistics and SCM } \\ \text { techniques } \\ \text { Standards of quality } \\ \text { Ethical procurement standards } \\ \end{array}$

Source(s): Based on Jahre and Fabbe-Costes (2015)

Service standardisation

Organisational standards 
different cases and focused on the different phases of kit management: (1) design, (2) supply and assembly, (3) deployment and (4) monitoring and evaluation. Field experience, technical and scientific knowledge together with strong cooperation between different organisations are required in the preparedness and evaluation phases to define the standardised set of items to include in a kit. Then, kits are packed according to standard practices and using standard packaging materials. This enables an optimal managing and handling of kits and optimal use of space in transport and warehousing. Standardisation also decreases the complexity of order management and increases response timeliness. According to UNICEF interviewed operators, standard utilisation enables organisations to talk with other organisations or partners since they speak the same language; everybody knows a specific kit's content. Even if kits sometimes contain goods that are not needed, the necessary ones are provided to beneficiaries, and the benefits connected to partners speaking the same language are achieved.

Some international humanitarian organisations have moved towards standardisation for the procurement of emergency materials, equipment, requirements and categorisation (Wilson et al., 2018) by publishing catalogues of standard items, including kits; for example, the UNHCR (United Nations High Commissioner for Refugees) core relief items catalogue (UNHCR, 2012), the IFRC (International Federation of Red Cross and Red Crescent Societies) standard products catalogue (IFRC, 2017), or the catalogue and brochure of DELSA (Disaster Emergency Logistics System for ASEAN) relief items (ASEAN, 2017). The benefits of standardisation that emergency logistics can derive from a joint catalogue are summarised in Table 2.

In addition to materials and equipment standardisation, procurement is a process that can be interested in the standardisation also in terms of ethical procurement. The elaboration of a set of shared ethical value standards recognised by NGOs is a challenging task. Even if the main principles of ethical procurement, such as human rights, green issues and child protection, are broadly recognised, to achieve an agreement on the definition of specific ethical procurement standards is a complicated objective (Wild and Zhou, 2011). The barriers to collaboration between NGOs are related to their heterogeneity in the purpose, function and cultural value; for instance, a different level of importance is accorded to the gender issues in different cultures, or there is a discrepancy between value-driven secular and faithbased NGOs.

The lack of logistics standards complicates horizontal cooperation between humanitarian organisations at different stages along the relief chain. Schulz and Blecken (2010) investigated
Standards in humanitarian supply chain

\footnotetext{
Benefits of standardisation

Supports the use of a common language in regard to the mobilisation of resources Creates homogeneity and reduces the overall number of items handled

Allows quick identification

Supports the selection of the most appropriate and the most cost-efficient items

Supports interoperability and inter-agency cooperation

Ensures compatibility between replacement items, equipment and spare parts

Facilitates sourcing and purchasing operations

Supports the continuity of item specifications over the longer term

Supports quality consistency

Allows economies of scale to be achieved

Facilitates physical distribution in terms of palatability, storability and portability

Can indicate recoverability or reparability of the item after use
}

Source(s): Wilson et al. (2018)

Table 2.

Benefits of standardisation through a shared catalogue 
JHLSCM 11,3

the potential synergies, gathered benefits and horizontal cooperation impediments in disaster relief logistics through cross-case analysis. Three cases were analysed combining the results of desk research and data obtained from semi-structured interviews and internal documentation: the United Nations Humanitarian Response Depots (UNHRD), The IFRC regional logistics units and the European Community Humanitarian Aid Department's (ECHO) humanitarian procurement centres. The study confirmed that logistics standards (in terms of standard services and standard relief items) could be seen as a technical precondition for horizontal cooperation in the disaster relief supply chain.

The need for standardisation in humanitarian logistics and supply chain also emerges from studies on performance measurement in the humanitarian supply chain. The demand for improvement, efficiency, accountability and transparency in disaster relief operations had increased the importance and interest in performance measurement (Abidi et al., 2014). Performance measurement in the humanitarian supply chain is more complex and less developed than in commercial supply chains, and commonly recognised performance measurement systems have not been developed for humanitarian logistics (D'Haene et al., 2015; Abidi and Scholten, 2015). Academics have proposed several indicators, but not much effort has been devoted to prioritising and synthesising indicators into an integrated performance measurement framework. There is a recognised problem of integration, standardisation and practicality in humanitarian supply chain performance measurement, and a standardised approach for reporting and benchmarking performance based on a selection of key performance indicators (KPIs) would support efficient data collection (Anjomshoae et al., 2019). Santarelli et al. (2015) proposed a holistic performance measurement system for performance evaluation of humanitarian supply chains. Standardisation is one of the KPIs included in the system, but empirical testing of the system demonstrated that a low percentage of contacted organisations affirm to use standard methods to solve operational problems.

The issue of standardisation naturally appears in academic studies connected with the logistics cluster. The logistics cluster is highly involved in the development of logistics standards and in ensuring that disaster relief follows existing guidelines and standards (Logistics Cluster, 2019a, b). Defining standards for basic logistics information and for logistics operating procedures is a challenging task. There is a general agreement on the need for standardisation, many documents and reports have been published, and a logistics operations guide has been developed that is available to anyone, but this is not considered enough (Jensen, 2012). In fact, in most cases, humanitarian operators do not have time to fully use the developed standards, and reading the guidance standard autonomously is not enough for a comprehensive understanding of them. In order to overcome these shortfalls, and to increase on operators' understanding and familiarisation with the defined concepts, the cluster lead carries out specific logistics response team training sessions in a simulated setting. Jahre and Jensen (2010) warned about the trade-offs between different types of coordination: coordination within clusters may imply an excessive functional focus and, consequently, inhibit coordination across clusters with a corresponding decrease of focus on overall beneficiary needs. Therefore, at a strategic level, both cluster and inter-cluster standards must be developed, used and promoted. With regard to the definition and the promotion of logistics guidelines and standards, the logistics cluster can gain relevant lessons from standards elements of the fourth-party logistics literature (Jensen, 2012).

Instead of highlighting the importance, the function and potential benefits of implementing standardisation, two studies show results that could constitute a contribution to the development and implementation of standards. Past natural disasters such as Hurricane Katrina (2005), the Haiti (2010) and the Nepal (2015) earthquakes highlighted the crucial role of airports in the disaster response phase. An airport can be utilised as a humanitarian logistics base by hosting a base camp, a staging area and a medical care area. Choi and Hanaoka (2017) focused on the first 
two types of facilities and proposed a method that enables planners to estimate the required space and to configure a layout. The method includes four main core phases: developing an adjacent diagram, estimating the area for each facility, developing a bubble diagram and developing a schematic plan. The results of the process should then be interpreted and selected. The authors also provide a confirmatory case study: the Shizuoka Airport in Japan. The method provides potential suggestions and support for the development of standards specific for airport based humanitarian logistics. Blecken (2010) proposed a supply chain process modelling method suitable to be applied by humanitarian organisations. From a preliminary empirical survey, it has been highlighted that only a small percentage of humanitarian organisations have reviewed and documented standardised processes. Starting from this gap, the author developed a reference task model that constitutes the basis for modelling and analysing humanitarian supply chain processes. The reference model differentiates two dimensions: hierarchical decomposition (including a strategic level, a tactical level and an operational level) and structural decomposition (including assessment, procurement, warehousing and transport). The framework aimed to help a systematic detection and assessment of the full collection of supply chain tasks of humanitarian organisations. It represents an interesting contribution to the standardisation of terms, definition and activities in humanitarian logistics and in supply chain.

Unlike most scientific contributions to the topic that take the form of qualitative research, Maghsoudi et al. (2018) performed a quantitative analysis to identify the effect of standardisation of operations in disaster relief supply chains. The authors collected survey data from 101 humanitarian organisations in the emerging countries within Southeast Asia and then used the structural equation modelling-partial least square (SEM-PLS) approach for data exploration. The performed analysis of the results revealed that standardisation has a significant impact on organisational performance outcomes in terms of resources used, responsiveness and flexibility.

Whereas papers focussing on standardisation of humanitarian logistics mainly describe the positive effects of such standardisation, there are also some authors and practitioners who identify opposing issues regarding the use and usefulness of logistics standards. In fact, process standardisation can also be related to a number of risks or disadvantages, such as loss of competitiveness, loss of flexibility, reduction and inhibition of creativity and improvisation, loss of independence, reduction of effectiveness of humanitarian relief and an increase in certification and bureaucratic costs (Blecken, 2010; Larson and Foropon, 2018). For example, the standardisation of healthcare relief goods may reduce the number of available suppliers and restrict the number and type of offered healthcare services; further, it can also impede providing equipment and drugs that meet national protocols and habits (McGuire, 2015). Jahre et al. (2015) presented three case studies on the application of organisational standards of logistics relevance developed by IFRC in disaster response in Haiti, Turkey and the Ivory Coast. As a result of the cross-case analysis, the authors advised of the need to pay attention to the requirements for local adaptation to take into account specific needs, available funding, local capacity and the general local context. A modular approach would be beneficial to increase efficiency, effectiveness and flexibility.

Instead of taking a position in the debate with those in favour of or with those against standardisation, Chandes and Paché (2010) suggested finding an optimal decoupling point between standardisation and adaptation and to moving towards an agile humanitarian supply chain. The humanitarian supply chain had to react quickly to humanitarian needs and, in the meantime, had to maintain the five components of an agile humanitarian supply chain, that is: volume flexibility, delivery flexibility, supply system flexibility, supply chain reactivity and flexibility of product portfolio.

\section{Research methodology}

Given the limited number of studies specifically focused on the topic and the need for humanitarian logistics standards perceived by most humanitarian actors and academics, an
Standards in humanitarian supply chain 
JHLSCM 11,3

explorative survey approach was implemented. There is a lack of survey research in studies focused on humanitarian relief (Kunz and Reiner, 2012; Burkart et al., 2016). Empirical methodologies such as surveys should be used more in order to increase knowledge in the humanitarian operation field (Banomyong et al., 2019). Researchers need to understand the reality of the humanitarian context and surveys enable them to properly represent its specific difficulties and features (Besiou and Van Wassenhove, 2015). The survey was conducted in order to identify the state of the art of logistics and supply chain standards in the context of humanitarian operations.

The development of the questionnaire included a test stage. The first version of the questionnaire was developed by a team comprised of representatives of academia and practice. The questionnaire was submitted to the pilot group of practitioners and academics who completed it in order to verify the intelligibility of the questions and to refine and complete the proposed multiple choices questions. The survey was revised based on information and suggestions collected from this pool of experts; humanitarian logistics practitioners and academics Answers from the pilot are not included in the findings.

The questionnaire (see Appendix for a list of survey questions) consisted of two main parts. The first section collected professional information about the respondents, including the type of organisation, specialisation, years of experience and geographical area of experience. The second part focused on the standards, and it aimed to collect the perception of importance for commonly recognised standards for humanitarian logistics and supply chain managers and their current use. The questionnaire structure included a 5-point Likert scale, multiple-choice questions and space for open answers (text format).

The eligibility criteria for survey participants were self-reported as being involved in the humanitarian logistics operations with a specific role in humanitarian logistics and supply chain activities. The survey was not focused on a specific category of professionals; its aim was rather to collect different views of academics and practitioners from various logistics areas. Therefore, a multimodal recruitment strategy was adopted instead of a simple random sample from an existing sampling frame. Requests to complete the online questionnaire were sent through emails to a selected mailing list of experts in the field and via social media (Facebook and Linkedin). The key factor in the distribution of the questionnaire was the communication from the Humanitarian Logistics Association (HLA), which is the largest network for humanitarian logistics practitioners. The responders included representatives of national and international non-profit organisations (NGO), United Nations agencies, commercial logistics and other private sector companies, civil protection or disaster management authorities and other national government agencies, inter-government authorities (e.g. ASEAN, EU, OAS, EAC), Institutional/statutory donors (not UN) and private donors or foundations, as well as military, academic or training organisations. Such a way of accessing respondents has its shortcomings, as the response rates are not possible to calculate. However, it enabled the collection of answers from a large and diverse group of professionals. This involvement of different groups of stakeholders allows researchers to provide a broader and neutral view of the research topic (Kovács and Moshtari, 2019).

The data collection was based on an online survey. The survey was accessible via the internet for a period of four months, from June to September 2019, resulting in 227 responses. At the end of the data collection, 223 questionnaires were available in the survey website repository. It is not possible to estimate the response rate because the exact population of practitioners and academics is unknown.

Descriptive statistics and nonparametric tests were used to analyse the data through the software SPSS (Statistical Package for the Social Sciences). The Kruskal-Wallis H test (also known as "one-way ANOVA on ranks") is a rank-based nonparametric test that has been used to determine statistically significant differences between groups of responders. In the case of significant differences between groups, a series of Mann-Whitney tests were 
performed as a post-hoc test to determine which pairs of groups differ significantly from one another. In fact, the Kruskal-Wallis $\mathrm{H}$ test is an omnibus test statistic and can only provide the information that at least two groups are different, without revealing which specific groups are statistically significantly different from each other.

\section{Results}

This section overviews results from the surveys. Figure 2 gives an overview of the sample responder's composition (more than a single answer was allowed).

There are three mainly represented categories:

(1) Over half of respondents were from $\mathrm{NGO}-51 \%=$ national (or provincial) nongovernmental or non-profit organisation (NGO) + International NGO;

(2) Commercial sector- $26 \%=$ commercial logistics company (national or international, including supplier of relief goods) + Other private sector companies;

(3) Academic or training organisations $-24 \%$.

Responders also indicated in which of the following branches they work or specialise (Table 3).

$62 \%$ of responders are humanitarian logistician/supply chain specialists; $40 \%$ indicated more than a single working area/specialization, while $23 \%$ more than two specialisations.

Figure 3 illustrates the geographical regions where the main work experience was gained (more than a single answer was allowed).

A high percentage of responders (71\%) have had experience in Africa, $41 \%$ in Europe, $37 \%$ in Asia and $31 \%$ in the Middle East. There is no relevant dependence between the number of regions where responders worked and the number of standards used. Those with more than ten years of reported working experience also had experience in a higher number of regions (Mann-Whitney, $p<0.000$ ); thus, they have been able to obtain experience in different parts of the world, frequently working for different organisations.

Civil protection, government and Intergovernment authorities

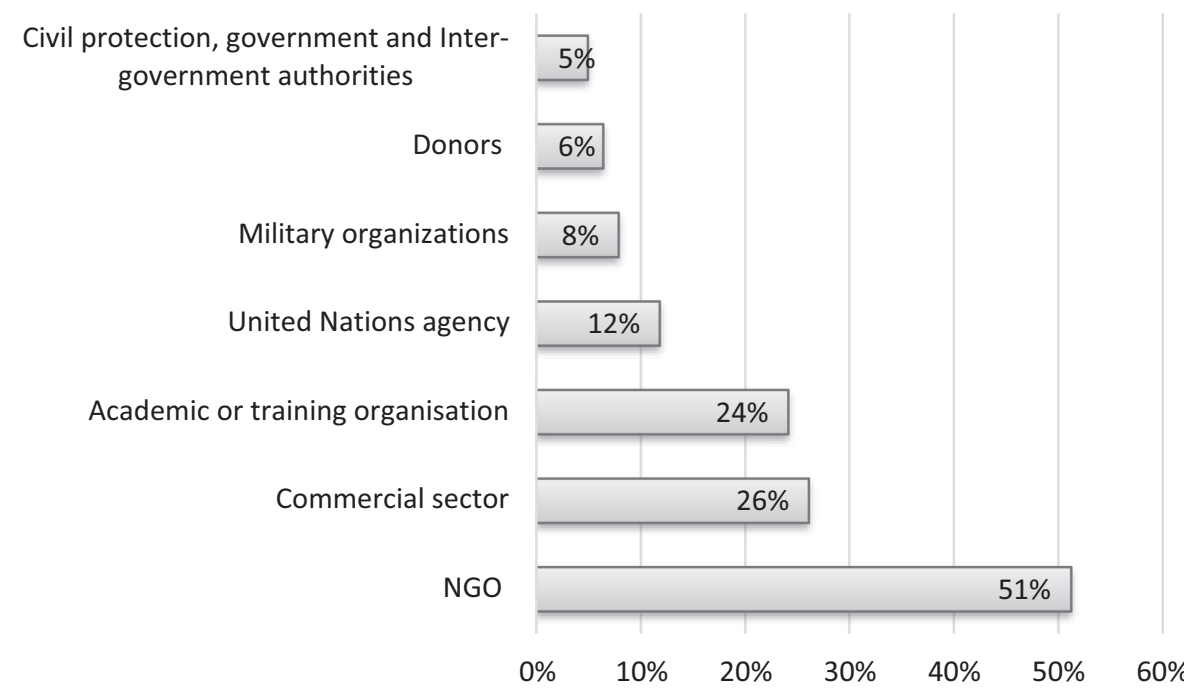

Figure 2. Sample responder's composition

Standards in humanitarian supply chain 
JHLSCM 11,3

560

Responders have been asked to indicate on a Likert scale from 1 to 5 , basing on their experience, how important the development of commonly recognised standards for humanitarian logistics and supply chain is.

As shown in Figure 4, 91\% of responders evaluate that the development of commonly recognised standards for humanitarian logistics and supply chain management is important $(25 \%)$ or very important $(66 \%)$.

The questionnaire next focused on how important common humanitarian logistics standards are considered in respect of different aspects of the supply chain and various phases (crises preparedness and response). Table 4 illustrates different aspects investigated and the percentage of answers for each of the possible values in the Likert scale (from 1 to 5).

The last column of Table 4 reports the percentage of responders that have assigned a 4 or a 5 to the specific aspect. The five areas with the perceived higher need for common humanitarian logistics standards (percentage of answers from 4 to 5 higher than $85 \%$ ) are:

(1) Procurement - procedures, donor requirements, tendering, ethical sourcing etc.;

(2) Distribution - design, safety and security etc.

Responders working area

Humanitarian logistician/supply chain specialist

Humanitarian procurement specialist

Humanitarian aid programme specialist

Vehicle fleet management specialist (aid sector or commercial)

Emergency services or search and rescue specialist

Commercial supply chain, transport or procurement specialist

Table 3.

Freight forwarding specialist

Responders

Infrastructure specialist (sea or airport, warehouse etc.)

Figure 3.

Geographical regions where working experience was gained

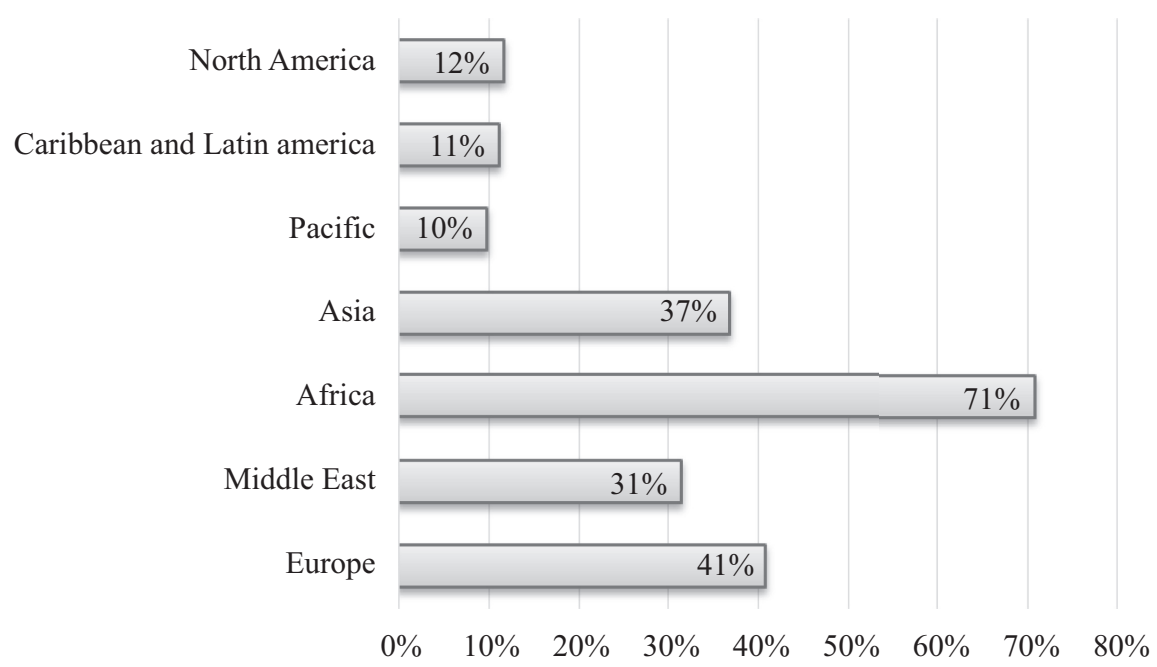


(3) Protection/safeguarding of staff, volunteers and beneficiaries in supply and logistics environments (during humanitarian logistics operations);

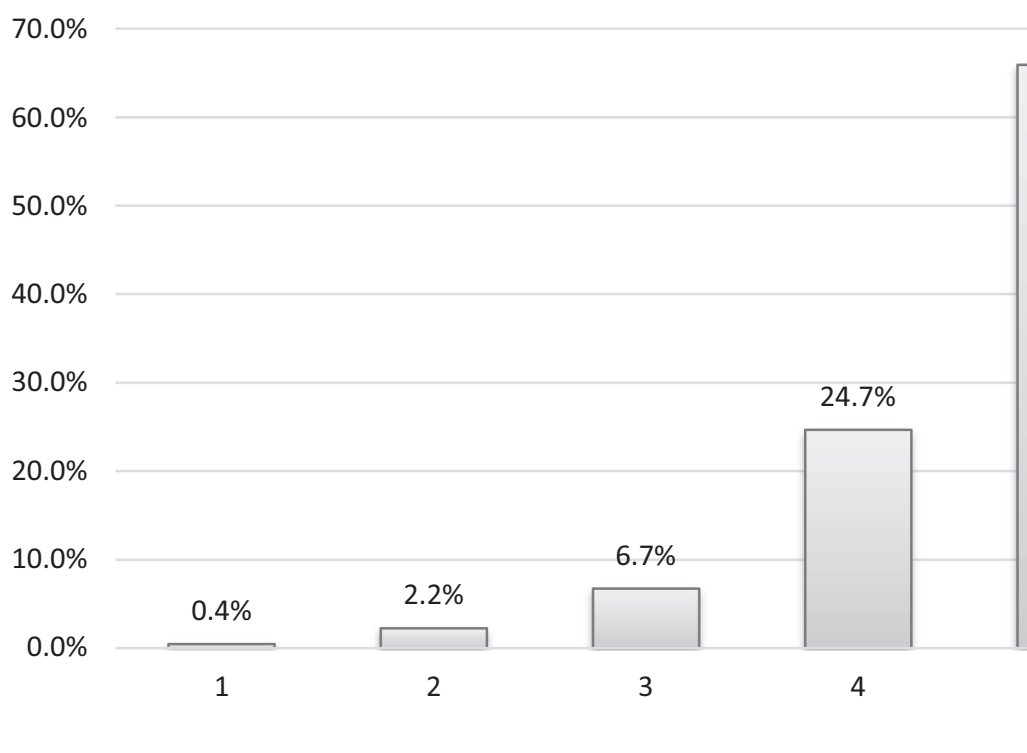

Standards in humanitarian supply chain

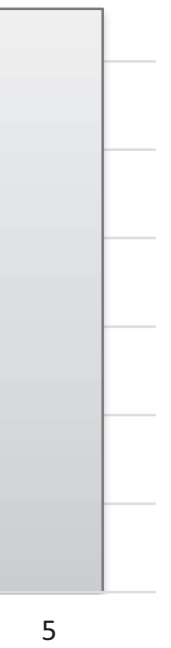

Figure 4. Importance attributed to the development of standards in humanitarian supply chain

\begin{tabular}{|c|c|c|c|c|c|c|c|}
\hline & 1 & 2 & 3 & 4 & 5 & $\begin{array}{l}\text { Sum } \\
4+5\end{array}$ & \\
\hline $\begin{array}{l}\text { Asset management - information and reporting, accounting, } \\
\text { disposal }\end{array}$ & $1 \%$ & $6 \%$ & $22 \%$ & $30 \%$ & $40 \%$ & $70 \%$ & \\
\hline $\begin{array}{l}\text { Procurement - procedures, donor requirements, tendering, } \\
\text { ethical sourcing etc. }\end{array}$ & $0 \%$ & $3 \%$ & $11 \%$ & $26 \%$ & $60 \%$ & $86 \%$ & \\
\hline $\begin{array}{l}\text { Eco/green logistics - e.g. material choices, waste management } \\
\text { and recycling (reverse logistics), carbon foot print }\end{array}$ & $4 \%$ & $9 \%$ & $23 \%$ & $34 \%$ & $30 \%$ & $64 \%$ & \\
\hline Market-based assistance including cash transfers & $2 \%$ & $8 \%$ & $24 \%$ & $39 \%$ & $27 \%$ & $66 \%$ & \\
\hline Warehousing - selection, design/layout, stock control etc. & $0 \%$ & $4 \%$ & $17 \%$ & $38 \%$ & $40 \%$ & $78 \%$ & \\
\hline Distribution - design, safety and security etc. & $0 \%$ & $3 \%$ & $8 \%$ & $37 \%$ & $52 \%$ & $89 \%$ & \\
\hline Subcontracted in-country cargo transport (all modes) & $3 \%$ & $8 \%$ & $21 \%$ & $38 \%$ & $31 \%$ & $69 \%$ & \\
\hline $\begin{array}{l}\text { Vehicle fleet management - fuel control, planning, vehicle } \\
\text { maintenance, driver controls etc. }\end{array}$ & $1 \%$ & $5 \%$ & $17 \%$ & $33 \%$ & $43 \%$ & $76 \%$ & \\
\hline $\begin{array}{l}\text { Logistics management controls - documentation, health and } \\
\text { safety, communications, human resources (competency and } \\
\text { learning pathway standards), monitoring and evaluation }\end{array}$ & $0 \%$ & $2 \%$ & $19 \%$ & $26 \%$ & $52 \%$ & $78 \%$ & \\
\hline $\begin{array}{l}\text { Protection/safeguarding of staff, volunteers and beneficiaries } \\
\text { in supply and logistics environments (during humanitarian } \\
\text { logistics operations) }\end{array}$ & $1 \%$ & $2 \%$ & $10 \%$ & $26 \%$ & $61 \%$ & $87 \%$ & \\
\hline Medical logistics - cold chain, inventory management etc. & $0 \%$ & $1 \%$ & $10 \%$ & $29 \%$ & $59 \%$ & $88 \%$ & \\
\hline Power supply - generator selection, solar power etc. & $2 \%$ & $4 \%$ & $19 \%$ & $41 \%$ & $33 \%$ & $74 \%$ & \\
\hline $\begin{array}{l}\text { Logistics planning - preparedness, needs assessment, } \\
\text { customs clearance, coordination etc. }\end{array}$ & $0 \%$ & $2 \%$ & $10 \%$ & $25 \%$ & $64 \%$ & $88 \%$ & $\begin{array}{r}\text { Table } 4 . \\
\text { Standards importance }\end{array}$ \\
\hline Sea and airport management & $3 \%$ & $9 \%$ & $17 \%$ & $39 \%$ & $33 \%$ & $72 \%$ & per logistics and \\
\hline Civil-military cooperation for logistics & $5 \%$ & $6 \%$ & $22 \%$ & $26 \%$ & $41 \%$ & $67 \%$ & supply chain area \\
\hline
\end{tabular}


JHLSCM 11,3
(4) Medical logistics - cold chain, inventory management etc.;

(5) Logistics planning - preparedness, needs assessment, customs clearance, coordination.

In addition, 11 out of 15 areas have response percentages form answers of 4 and 5 higher than $70 \%$. This suggests that the importance of the introduction of standards in humanitarian logistics is perceived as a cross-cutting need: a necessity for different parts and aspects of the whole supply chain. From the top five standards, two are related to potentially lifesaving activities (protection and medical logistics), while the remaining three cover key supply chain functions: planning, procurement and distribution. Further responders also specified, in open comments that other humanitarian logistics activities should be considered for standardisation, included: supply chain exposures and risks mitigation measures, security and risk management, office opening and set up and exit strategies, electronic warehouse management inventory and supply chain management systems and use of technology in humanitarian logistics, integration/involvement with programme planning, packaging and branding to allow sharing prepositioned inventory, processes related to quality assurance and value analysis/management, standards and considerations for disability inclusion as well in disaster preparedness and response, communication and coordination among humanitarian actors, supply chain data management, analysis and presentation to aid in evidence based management, management Information Systems, grassroots groups management, evacuation procedures and people transport for evacuation and relocation, interactions with private sector, partnering with local NGOs/Civil Society/Governments and national government, goods in transit, track and trace.

A focus on the 21 responders who gave a score equal to 1,2 , or 3 to the development of commonly recognised standards shows interesting results. 15 participants have working experience equal or longer than 10 years, and 17 are used to use existing standards. When asked to do the same importance attribution for the 15 logistics and supply chain areas (Table 3), the responders provided unexpected answers: from over 315 evaluations (21 responders*15 sectors), 4 or 5 are the attributed scores of $57 \%$ of them. Each responder indicated between at least 1 sector and up to 14 sectors, where the use of common logistics standards is considered important (4) or very important (5).

Moreover, responders were asked to list up to five technical procurement/logistics/supply chain standards that they use or refer to frequently in their work. 39 respondents from among 223 standards $(17 \%)$ did not specify any of them; $64 \%$ of responders have more $(>$ or $=)$ than 10 years of professional work experience. Figure 5 indicates the percentage of each category of responders that have not specified any technical standards: 43 and $26 \%$ of responders are from military and commercial organisations respectively.

Figure 6 summarises the standards mainly used in humanitarian logistics and supply chain.

The Sphere standards are those mainly used in the sector, even though such standards are not specific for logistics and supply chain processes. 38\% of responders use more than one standard.

For each of the main standards reported, Table 5 illustrates the number of people indicating the standard and the percentage of people that use the specific standard without combining it with other standards.

It is clear that there is a lack of uniformity in the use of standards, the use of standards that are not specific for the logistics and supply chain sectors and also approaches that are not strictly standards, such as the CILT/Frits Institute. This underlines that there is a need for a shared reference point and the adhesion to a common, specific and recognised standard for the given topic. 
Considering exclusively those who indicated only 1 professional sector $(N=205$ over 223$)$, by using the Kruskal-Wallis Test, it is possible to state that there is homogeneity between different groups of professionals with regard to the relevance assigned to the development of standards (no significant difference between groups, $p>0.05$ for the 3-group categorisation). Similarly, opinions about the relevance of standards development does not show a significant difference if we address more or less experienced practitioners: there is no significant difference between responders with less or more than 10 years of experience.
Standards in humanitarian supply chain
Civil protection, government and Intergovernment authorities

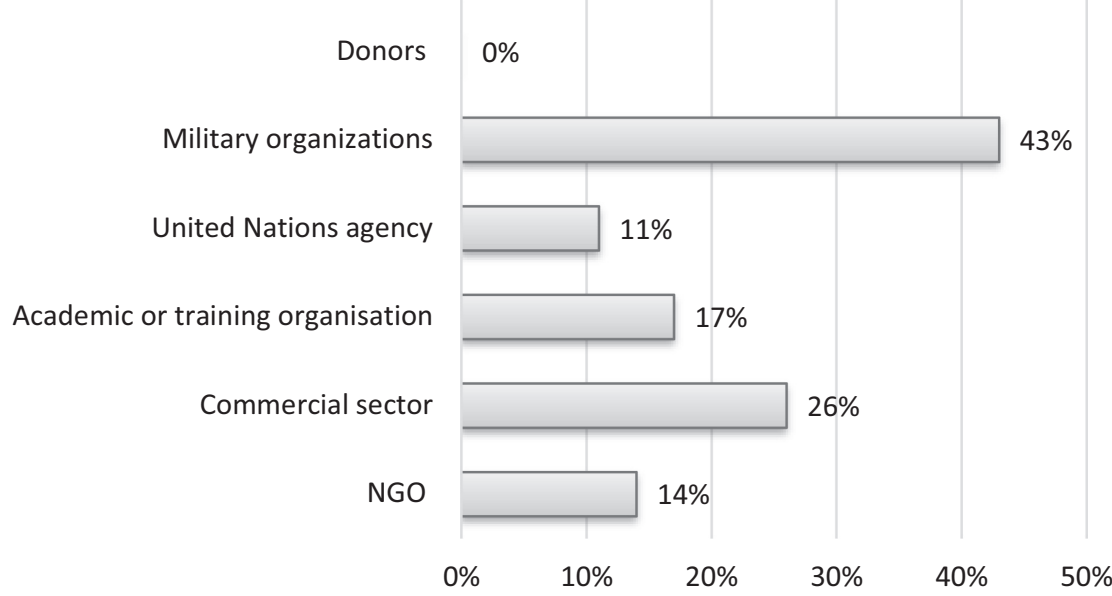

Figure 5.

Percentage of each category of responders that have not specified any technical standards

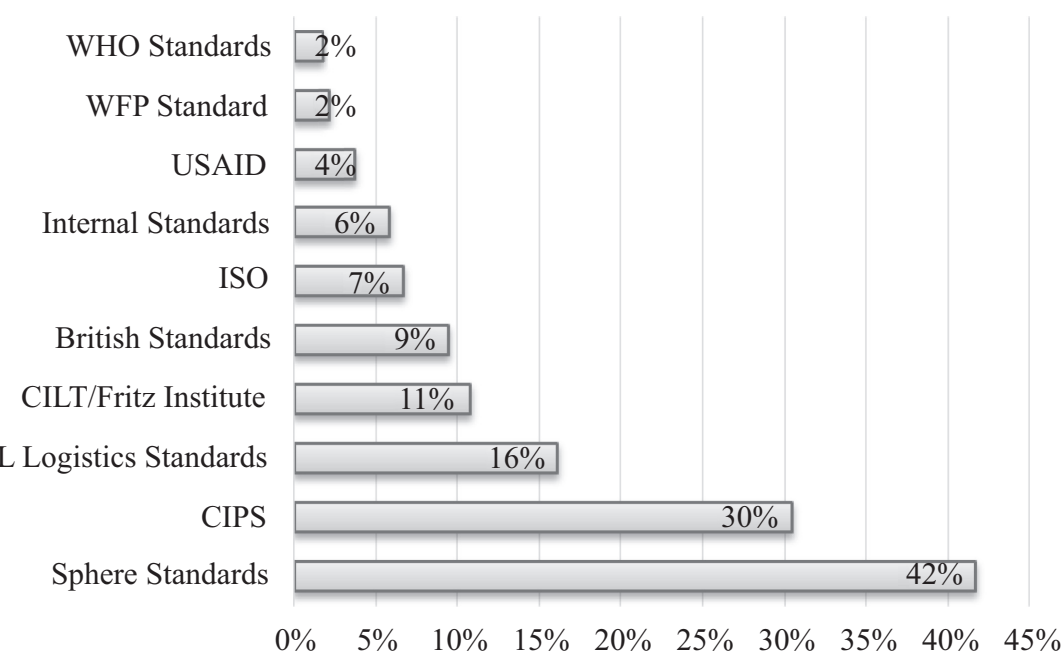

Figure 6. Standards used in humanitarian logistics and supply chain 


\section{JHLSCM 11,3}

Standard

$N^{\circ}$ of responders using the standard

Sphere standards

USAID

ISO

564

British standards

WFP standard

WHO standards

CILT/Fritz Institute

CIPS

Table 5.

Responders that use just one standard
Internal standards

PARCEL logistics

standards
$\%$ Of responders using the standard alone, without combining it with other standards

This suggests that the importance attached to the development of standards is shared by different actors of the humanitarian system: all of the professional categories recognise high importance of the future development of HLSCS, and this importance is also crosswise recognised, irrespective of the actors' work experience.

A Mann-Whitney Test has been designed using "standards used" as test variables and "the geographical region where main work experience has been gained" as a grouping variable. Responders with no experience in Europe infrequently use ISO (significant difference between those with experience and no experience in Europe $p$ value $=0.008$ ).

Kruskal-Wallis test has been performed in order to evaluate whether the three main categories of responders use different standards. The outputs of the analysis are summarised in Table 6: for each standard, the three main output of the Kruskal-Wallis test are reported: the chi-squared value (Chi-Square), the degrees of freedom of the test (df) and the $p$ value (Asymp.Sig.).

The Kruskal-Wallis test showed that there was a statistically significant difference in the use of Sphere standards, ISO, British and Parcel between different professional groups $(p<0.05)$. The ranks values for each standard and for each profession group (NGO, Commercial sector, Academic or training organisations) are reported in Table 7.

Subsequently, the Mann-Whitney post-hoc test (done on test variables with a significant $p$-value, $p<0.005)$, illustrated which groups showed a substantial difference. The use of Sphere and Parcel standards is more common between NGO operators than in commercial and academic/training sectors. The use of ISO standards is more common between commercial operators than between NGO operators, but there is no significant difference with reference to academics. The use of British standards is more common between commercial operators than between NGO operators and academics/trainers.

\section{Conclusions}

Both the literature review and the questionnaire results led to the perceived necessity of developing specific standards for humanitarian logistics and supply chain. The interest in the topics and its relevance is also confirmed by the launch in 2019 of the project "Development of Best Practice and Universal Standards for Humanitarian Transport and Logistics" aimed to achieve agreed shared principles and guidance to support good practices in logistics (INSPIRE, 2019). Coming back to research questions and to what emerges from the performed analysis, we can summarise the paper results as follow. 


\begin{tabular}{|c|c|c|c|c|}
\hline \multirow{5}{*}{$\begin{array}{l}\text { JHLSCM } \\
11,3\end{array}$} & & Profession group & $N$ & Mean rank \\
\hline & Sphere & 1 & 80 & 90.50 \\
\hline & & 2 & 39 & 61.88 \\
\hline & & 3 & 36 & 67.68 \\
\hline & & Total & 155 & \\
\hline \multirow{10}{*}{566} & ISO & 1 & 81 & 74.39 \\
\hline & & 2 & 39 & 85.50 \\
\hline & & 3 & 36 & 80.17 \\
\hline & & Total & 156 & \\
\hline & BRITISH & 1 & 81 & 73.89 \\
\hline & & 2 & 39 & 93.00 \\
\hline & & 3 & 36 & 73.17 \\
\hline & & Total & 156 & \\
\hline & PARCEL & 1 & 81 & 85.65 \\
\hline & & 2 & 39 & 69.50 \\
\hline Table 7. & & 3 & 36 & 72.17 \\
\hline Rank values & & Total & 156 & \\
\hline
\end{tabular}

5.1 Identify current knowledge and approaches to the topic by the academic community Academic research efforts to classify standards in the humanitarian context highlighted the areas that can be involved in the standardisation process, as confirmed by the survey answers. Most of the authors use the case study or cross-case analysis to analyse standardisation in humanitarian logistics. These approaches enabled researchers to identify the connected benefits and weaknesses, contingency factors connected to the use of standards, negative consequences of lack of standardisation and difficulties in implementation. This includes potential tradeoff between increased standardisation and possibility to localise humanitarian operations. At the current state, the development and implementation of standards/standardisation are still identified as a research gap in humanitarian logistics and supply chain management.

\subsection{Evaluate the current use of standards by humanitarian logistics practitioners}

Major international humanitarian actors recently demonstrated their interest and active involvement in the humanitarian logistics standardisation process. From the survey that involved different groups of stakeholders, allowing a wide and neutral view of the research topic, it emerges that most of the practitioners use a standard that is not specific for logistics and supply chain processes: the Sphere standards. CIPS, PARCEL Logistics Standards, CIL T/Fritz Institute, British Standards, ISO, Internal Standards, USAID, WFP Standard, WHO Standards are the other standards used in humanitarian logistics and supply chain (listed in decrescent order of use). It is remarkable that most of them are not specific for the sector, and some of them are neither "standards". Sphere and Parcel standards are mainly used by NGO operators, while ISO and British standards are more common between commercial organisations. Standards are mainly used in combination with other standards: practitioners often use different standards as a guide in the performed operations. This seems to suggest the lack of a specific standard covering all the areas of the logistics and supply chain that are responding to the users' needs.

\subsection{Investigate the perceived need for further humanitarian logistics and supply chain standards (HLSCS)}

The necessity of developing commonly recognised standards for humanitarian logistics and supply chain management clearly emerged from the survey as $91 \%$ of responders evaluate 
this process as important or very important. "Procurement", "Distribution", "Protection/ safeguarding of staff, volunteers and beneficiaries in supply and logistics environments", "Medical logistics" and "Logistics planning - preparedness, needs assessment, customs clearance, coordination" are the logistics and supply chain areas with the perceived higher need for common humanitarian logistics standards, but also the other areas proposed are evaluated as important or very important by most of responders. In addition, other areas have been suggested. This highlight that the need of standard in not confined to specific sectors of the supply chain, but it is a wide-ranging need.

The HLSCS could be developed in the form of voluntary "minimum standards for humanitarian logistics and supply chain", which is following the Sphere approach, and so they could include standards, key actions, key indicators and guidance notes to achieve them. The "minimum standards for humanitarian logistics and supply chain" might become part of the Humanitarian Standards Partnership (HSP). As for other initiatives of the HSP, the minimum standards for humanitarian logistics and supply chain might share a rights-based approach and might be developed in a consultative and consensus-based manner. "Minimum standards for humanitarian logistics and supply chain" might fill the gap in the existing standard for humanitarian operations and complementing the HSP initiatives by providing specific guidance on only scattered and partially covered in the current standards. Another option is to apply commercial standards in humanitarian settings, as minimum standards from the humanitarian sector should not contradict those from the commercial sector during the response. As there is a frequent need for cooperation between humanitarian and commercial actors, standards should stimulate such cooperation. To stimulate cooperation it is important to note that too much standardisation, and the compulsory use of standards, may create additional barriers in cooperation. Thus the voluntary character of standards and possibility for step-by step implementation might play key role in implementation, especially among smaller organisations, such as local partners.

The survey reveals that existing standards that are not included in the Humanitarian Standards Partnership are not used by many operators. Therefore, it would not be useful to put efforts into the development of a new standard that would not be coordinated with the existing ones. There is need for coordination with existing initiatives.

The development of a specific standard alone cannot be sufficient for the sharing and the use of standards among the humanitarian community (Jensen, 2012; Jahre et al., 2015). The developing phase should run in parallel with the design of a plan for a logistics standard diffusion and training. When developing standards it is needed to account for the differences between humanitarian actors, listening also local, national, level organisations. Standards should be flexible enough to be adopted by local partners, as whole, or partially, thus modular standards could be solution. Only in such situation standardisation will support localisation of humanitarian operations. Different actions should be taken simultaneously: documents that are complete and easy to understand and consult (Ibegbunam and McGill, 2012) should be written; training should be designed in the form of a traditional workshop, online courses and simulation activities; further, it would also be effective to contact academics responsible for logistics training and to ensure the inclusion of the logistics standard in the courses programs. Documents, training and other actions also should reflect the diversity of humanitarian organisations, being designed for specific groups (i.e. local NGOs.). A crucial factor for the development and the concrete use of efficient HLSCS is that the focus should be maintained on the real objective of a humanitarian logistics process, which is, saving lives and reducing the suffering of affected people. The focus on the main and shared objective would reduce the debate on standards and the "conflict" between standardisation supporters and opponents. The standardisation is just a tool, and so the attention should not be on the standardisation itself but on the final goal to achieve. There is a need for a balance between standardisation that supports cooperation and "overstandardisation" that will exclude some
Standards in humanitarian supply chain 
JHLSCM 11,3

organisations (i.e. smaller, local organisations without resources to implement compulsory standards).

The results of the research also indicate some future research possibilities; this includes an in-depth analysis of standards usage, applying case study, as well as focus on specific areas, such as standards in information exchange, packaging, processes, with a focus on both physical and organisational standards (Jahre and Fabbe-Costes, 2015). Another field is to look at standards used between actors that are already using their own standards (i.e. commercial, military) to find how such standards are interoperable with humanitarian standards.

Then, it is worth looking at the downside of standardization, what the risks related to standards usage are, and what their impact is on process flexibility responsiveness and innovation (Blecken, 2010; Larson and Foropon, 2018). There is also need for the further analysis of standards adoption among national-level organisations (including implementing partners). As indicated by Jahre et al. (2015) when designing standards local needs and context should be taken for consideration. Without "localising" standards, it will be hard to support localisation. This should be reflected in future research, for example looking of how smaller, local, organisations are implementing standards and impact of such implementation on their involvement in humanitarian supply chains. When researching standardisation, the key is to look at the impact of the whole supply chain and the beneficiaries to assure that promised benefits of standardisation are achieved.

\section{References}

Abidi, H., de Leeuw, S. and Klumpp, M. (2014), "Humanitarian supply chain performance management: a systematic literature review", Supply Chain Management: International Journal, Vol. 19 Nos 5-6, pp. 592-608.

Abidi, H. and Scholten, K. (2015), "Applicability of performance measurement systems to humanitarian supply chains", in Klumpp, M., de Leeuw, S., Regattieri, A. and de Souza, R. (Eds), Humanitarian Logistics and Sustainability, Lecture Notes in Logistics, Springer, Cham, pp. 235-260.

Anjomshoae, A., Hassan, A. and Wong, K.Y. (2019), "An integrated AHP-based scheme for performance measurement in humanitarian supply chains", International Journal of Productivity and Performance Management, Vol. 68 No. 5, pp. 938-957.

Coordinating Centre for Humanitarian Assistance on disaster management ASEAN (2017), "Catalogue and brochure of DELSA relief items", available at: https://ahacentre.org/wp-content/uploads/ 2017/03/AHACatalogue_Draft-09_highres_FA.compressed.pdf (accessed 15 February 2020).

Banomyong, R., Varadejsatitwong, P. and Oloruntoba, R. (2019), "A systematic review of humanitarian operations, humanitarian logistics and humanitarian supply chain performance literature 2005 to 2016”, Annals of Operations Research, Vol. 283 Nos 1-2, pp. 71-86.

Besiou, M. and Van Wassenhove, L.N. (2015), "Addressing the challenge of modeling for decisionmaking in socially responsible operations", Production and Operations Management, Vol. 24 No. 9, pp. 1390-1401.

Blecken, A. (2010), "Supply chain process modelling for humanitarian organizations", International Journal of Physical Distribution and Logistics Management, Vol. 40 Nos 8-9, pp. 675-692.

Burkart, C., Besiou, M. and Wakolbinger, T. (2016), "The funding - humanitarian supply chain interface", Surveys in Operations Research and Management Science, Vol. 21 No. 2, pp. 31-45.

Chandes, J. and Paché, G. (2010), "Investigating humanitarian logistics issues: from operations management to strategic action”, Journal of Manufacturing Technology Management, Vol. 21 No. 3, pp. 320-340.

Choi, S. and Hanaoka, S. (2017), "Diagramming development for a base camp and staging area in a humanitarian logistics base airport", Journal of Humanitarian Logistics and Supply Chain Management, Vol. 7 No. 2, pp. 152-171. 
D'Haene, C., Verlinde, S. and Macharis, C. (2015), "Measuring while moving (humanitarian supply chain performance measurement - status of research and current practice)", Journal of Humanitarian Logistics and Supply Chain Management, Vol. 5 No. 2, pp. 146-161.

Fabbe-Costes, N., Jahre, M. and Rouquet, A. (2006), "Interacting standards: a basic element in logistics networks", International Journal of Physical Distribution and Logistics Management, Vol. 36 No. 2, pp. 93-111.

Fritz Institute (2004) Proceedings of the Humanitarian Logistics Conference - Africa Region 2004, 20-21 September, Nairobi, available at http://www.fritzinstitute.org/prgSC-HLCaf2004proceedings.htm (accessed 12 December 2019).

Ibegbunam, I. and McGill, D. (2012), "Health commodities management system: priorities and challenges", Journal of Humanitarian Logistics and Supply Chain Management, Vol. 2 No. 2, pp. 161-182.

International Federation of Red Cross and Red Crescent Societies (IFRC) (2017), "Standard products catalogue", available at: https://itemscatalogue.redcross.int/ (accessed 15 February 2020).

INSPIRE Consortium (2019), "Development of best practice and universal standards for humanitarian transport and logistics", available at: http://ul-standards.org/Docs/Executive_Summary.pdf (accessed 15 February 2020).

Itiola, A.J., Obi, C., Mohammed, A., Raji, J., Ibegbunam, I., Aguora, S. and Odelola, B. (2019), "Institutionalization of stock status report in the management of HIV/AIDS programme: experience from Nigeria”, Journal of Global Health Reports, Vol. 3, e2019010, doi: 10.29392/joghr. 3.e2019010.

Jahre, M. and Fabbe-Costes, N. (2015), "How standards and modularity can improve humanitarian supply chain responsiveness: the case of emergency response units", Journal of Humanitarian Logistics and Supply Chain Management, Vol. 5 No. 3, pp. 348-386.

Jahre, M., Ergun, O. and Goentzel, J. (2015), "One size fits all? Using standard global tools in humanitarian logistics", Procedia Engineering, Vol. 107, pp. 18-26.

Jahre, M. and Jensen, L.-M. (2010), "Coordination in humanitarian logistics through clusters", International Journal of Physical Distribution and Logistics Management, Vol. 40 Nos 8-9, pp. 657-674.

Jensen, L.-M. (2012), "Humanitarian cluster leads: lessons from 4PLs", Journal of Humanitarian Logistics and Supply Chain Management, Vol. 2 No. 2, pp. 148-160.

Kapucu, N. (2006), "Emergency logistics planning and disaster preparedness", Journal of Emergency Management, Vol. 4 No. 6, pp. 21-24.

Kapucu, N., Lawther, W.C. and Pattison, S. (2007), "Logistics and staging areas in managing disasters and emergencies", Journal of Homeland Security and Emergency Management, Vol. 4 No. 2, Article 3.

Kovács, G. and Moshtari, M. (2019), "A roadmap for higher research quality in humanitarian operations: a methodological perspective”, European Journal of Operational Research, Vol. 276 No. 2, pp. 395-408.

Kovács, G. and Spens, K. (2009), "Identifying challenges in humanitarian logistics", International Journal of Physical Distribution and Logistics Management, Vol. 39 No. 6, pp. 506-528.

Kovács, G. and Spens, K.M. (2011a), "Humanitarian logistics and supply chain management: the start of a new journal", Journal of Humanitarian Logistics and Supply Chain Management, Vol. 1 No. 1, pp. 5-14.

Kovács, G. and Spens, K.M. (2011b), "Trends and developments in humanitarian logistics - a gap analysis", International Journal of Physical Distribution and Logistics Management, Vol. 41 No. 1, pp. 32-45.

Kumar, S., Niedan-Olsen, K. and Peterson, L. (2009), "Educating the supply chain logistics for humanitarian efforts in Africa: a case study", International Journal of Productivity and Performance Management, Vol. 58 No. 5, pp. 480-500. 
JHLSCM 11,3

Kunz, N. and Reiner, G. (2012), "A meta-analysis of humanitarian logistics research", Journal of Humanitarian Logistics and Supply Chain Management, Vol. 2 No. 2, pp. 116-147.

Larson, P.D. and Foropon, C. (2018), "Process improvement in humanitarian operations: an organisational theory perspective", International Journal of Production Research, Vol. 56 No. 21, pp. 6828-6841.

Logistics Cluster (2019a), "Logistics cluster annual report 2018”, available at: https://logcluster.org/ sites/default/files/logisticscluster_annualreport_2018_0.pdf.

Logistics Cluster (2019b), “Logistics cluster strategy 2016-2021”, available at: https://logcluster.org/ sites/default/files/logistics_cluster_strategy_2016_2021.pdf.

Maghsoudi, A., Zailani, S., Ramayah, T. and Pazirandeh, A. (2018), "Coordination of efforts in disaster relief supply chains: the moderating role of resource scarcity and redundancy", International Journal of Logistics Research and Applications, Vol. 21 No. 4, pp. 407-430.

Maon, F., Lindgreen, A. and Vanhamme, J. (2009), "Developing supply chains in disaster relief operations through cross-sector socially oriented collaborations: a theoretical model", Supply Chain Management: International Journal, Vol. 14 No. 2, pp. 149-164.

McGuire, G. (2015), Handbook of Health Care Logistics, 3rd ed., available at: www. humanitarianhealthcarelogistics.com/handbook.htm (accessed 24 February 2020).

O’Donnell, M.R., Bacos, D. and Bennish, M.L. (2002), "Nutritional response to the 1998 Bangladesh flood disaster: sphere minimum standards in disaster response", Disasters, Vol. 26 No. 3, pp. 229-241.

OECD (Organisation for Economic Co-operation and Development) (2017), "Localising the response. World humanitarian summit. Putting policy into practice", available at: https://www.oecd.org/ development/humanitarian-donors/docs/Localisingtheresponse.pdf (accessed 14th January 2021).

Oloruntoba, R. and Gray, R. (2006), “Humanitarian aid: an agile supply chain?”, Supply Chain Management, Vol. 11 No. 2, pp. 115-120.

Piotrowicz, W.D. (2018), "In-kind donations, cash transfers and local procurement in the logistics of caring for internally displaced persons", Journal of Humanitarian Logistics and Supply Chain Management, Vol. 8 No. 3, pp. 374-397.

Santarelli, G., Abidi, H., Klumpp, M. and Regattieri, A. (2015), "Humanitarian supply chains and performance measurement schemes in practice", International Journal of Productivity and Performance Management, Vol. 64 No. 6, pp. 784-810.

Scholten, K., Sharkey Scott, P. and Fynes, B. (2014), "Mitigation processes - antecedents for building supply chain resilience", Supply Chain Management: International Journal, Vol. 19 No. 2, pp. 211-228.

Schulz, S.F. and Blecken, A. (2010), "Horizontal cooperation in disaster relief logistics: benefits and impediments", International Journal of Physical Distribution and Logistics Management, Vol. 40 Nos 8-9, pp. 636-656.

Tatham, P. and Spens, K. (2011), "Towards a humanitarian logistics knowledge management system”, Disaster Prevention and Management: International Journal, Vol. 20 No. 1, pp. 6-26.

Thomas, A. and Kopczak, L. (2005), "From logistics to supply chain management: the path forward in the humanitarian sector", White paper, Fritz Institute, San Francisco, California.

Tomasini, R.M. and Van Wassenhove, L.N. (2009), Humanitarian Logistics, Palgrave Macmillan.

United Nations High Commissioner for Refugees (UNHCR) (2012), "UNHCR core relief items catalogue", available at: https://www.sheltercluster.org/sites/default/files/docs/UNHCR\%20Core \%20Relief\%20Items\%20Catalogue.pdf (accessed 15 February 2020).

Vaillancourt, A. (2016), "Kit management in humanitarian supply chains", International Journal of Disaster Risk Reduction, Vol. 18, pp. 64-71.

van Wassenhove, L.N. (2006), "Humanitarian aid logistics: supply chain management in high gear", Journal of the Operational Research Society, Vol. 57 No. 5, pp. 475-489. 
WHO, New Delhi, India (2007), "Benchmarks, standards and indicators for emergency preparedness and response, emergency and humanitarian action", available at: http://origin.searo.who.int/ entity/emergencies/ehabenchmarks.pdf (accessed 12th December 2019).

WHS (2016), “Commitments to action”, World Humanitarian Summit, Istanbul, 23-24 May 2016, available at: https://agendaforhumanity.org/sites/default/files/resources/2017/Jul/WHS_ commitment_to_Action_8September2016.pdf (accessed 14 January 2021).

Wild, N. and Zhou, L. (2011), "Ethical procurement strategies for international aid non-government organisations", Supply Chain Management: International Journal, Vol. 16 No. 2, pp. 110-127.

Standards in humanitarian supply chain

Wilson, M.M.J., Tatham, P., Payne, J., L’Hermitte, C. and Shapland, M. (2018), "Best practice relief supply for emergency services in a developed economy: evidence from Queensland Australia", Journal of Humanitarian Logistics and Supply Chain Management, Vol. 8 No. 1, pp. 107-132.

Ye, Y., Wen, J. and Hong, Y. (2020), "Managing relief inventories responding to natural disasters: gaps between practice and literature", Production and Operations Management, Vol. 29 No. 4, pp. 807-832. 


\section{JHLSCM 11,3 \\ Appendix \\ Survey questions}

\section{2}

1. Which of the following do you represent? (Please indicate all that apply):

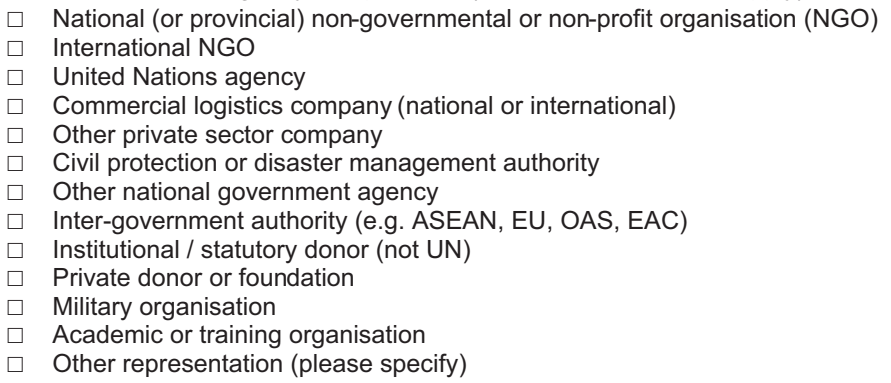

2. Your Profession: Which of the following do you work as or are specialising in? (Please indicate all that apply):

$\square$ Humanitarian logistician / supply chain specialist

$\square$ Humanitarian procurement specialist

$\square$ Humanitarian aid programme specialist

$\square \quad$ Vehicle fleet management specialist (aid sector or commercial)

$\square$ Emergency services or search and rescue specialist

$\square$ Commercial supply chain, transport or procurement specialist

$\square \quad$ Freight forwarding specialist

$\square \quad$ Infrastructure specialist (sea or airport, warehouse etc.)

$\square \quad$ Safety and Security specialist (aid or commercial)

$\square \quad$ Other Profession(please specify)

3. Please indicate the number of years of professional work experience.

4. Please select geographical region(s) where main work experience gained (with longer work experience):

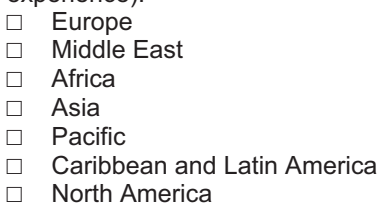

5. Based on your experience, how important do you believe the development $f$ commonly recognised standards for humanitarian logistics and supply chain management to be? Tick one (where 1 is least important and 5 is very important).

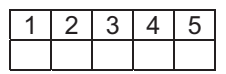

6. Please list up to 5 technical procurement/logistics/supply chain standards that you use or refrence frequently in your work. 
7. How important do you consider common humanitarian logistics standards to be in respect of crises preparedness and response, for each of the following? Tick one answer per line (where 1 is least important and 5 is very important)

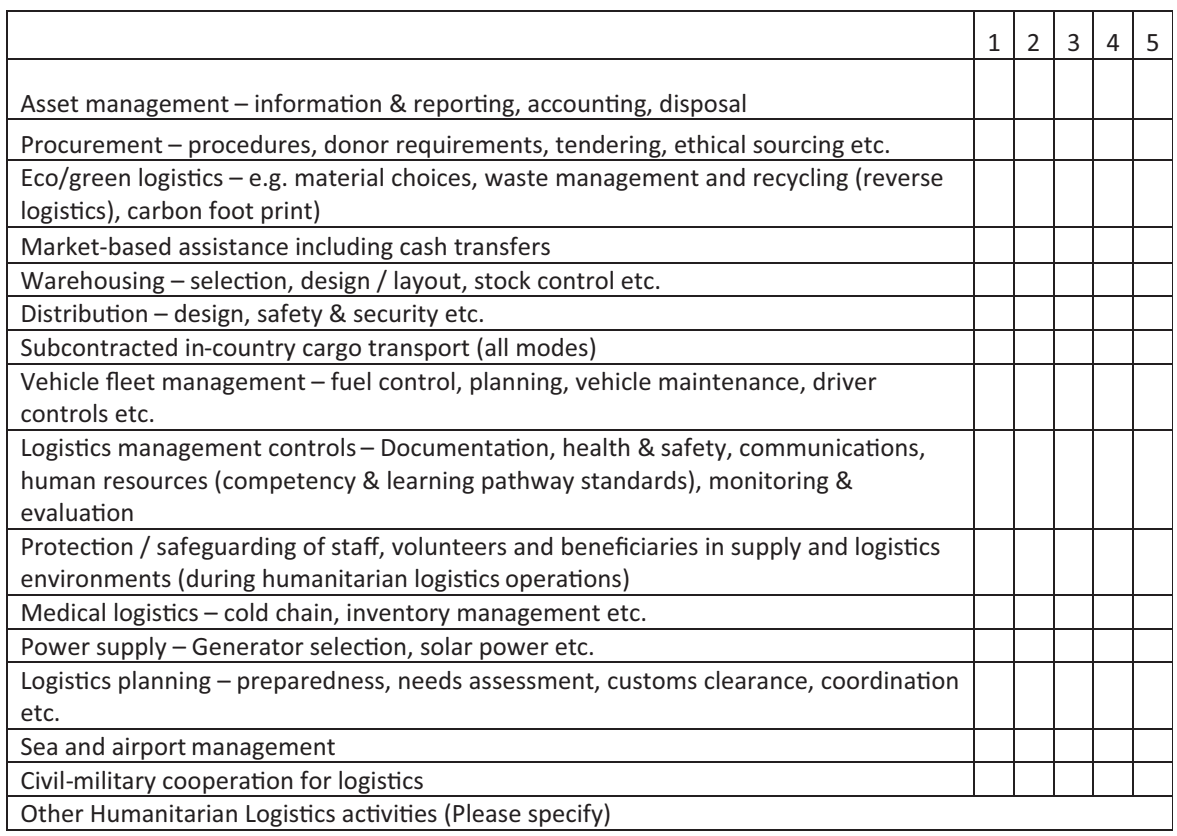

Standards in humanitarian supply chain

\section{Corresponding author}

Claudia Paciarotti can be contacted at: c.paciarotti@univpm.it

For instructions on how to order reprints of this article, please visit our website:

www.emeraldgrouppublishing.com/licensing/reprints.htm

Or contact us for further details: permissions@emeraldinsight.com 